\title{
Opsonic Activity of Cord Serum-an Evaluation Based on Determination of Oxygen Consumption by Leukocytes
}

\author{
YOHNOSUKE KOBAYASHI ${ }^{(24)}$ AND TOMOFUSA USUI \\ Department of Pediatrics, Hiroshima University School of Medicine, Hiroshima 734, Japan
}

\begin{abstract}
Summary
Opsonic activity against four kinds of particles was compared between adult and cord sera by determining the oxygen consumption capacity of leukocytes. Although both sera had almost equal activity against killed $E$. coli (adult: $1.5 \pm 0.6$, and cord: $1.6 \pm 0.3$ at $10 \%$ serum concentration, respectively, when expressed in nmoles oxygen consumed $/ \mathrm{min} / 10^{6} \mathrm{PMNL}$ ), cord serum showed less activity against zymosan (adult: $7.1 \pm 2.3$ and cord: $4.9 \pm 2.0$ ) and killed $S$. aureus 209P (adult: $4.7 \pm 0.8$ and cord: $2.5 \pm 0.6$ ) when diluted below $10 \%$ and $1 \%$, respectively. However, this difference was not prominent when the serum concentration was higher in the reaction system. No opsonic activity against $S$. faecalis (either killed or live) was present in any cord serum tested (adult: $2.7 \pm 0.6$ and cord: 0 , respectively at $5 \%$ serum concentration).

Oxygen consumption capacity was compared between adult and cord leukocytes with opsonins in pooled adult serum and zymosan and $S$. aureus 209P as phagocytizable particles. Although no distinction was found at higher serum concentrations (adult: 7.5 \pm 0.9 and cord: $6.9 \pm 1.1$ for zymosan at $10 \%$ and adult: $4.6 \pm 0.9$ and cord: $4.3 \pm 1.0$ for $S$. aureus $209 \mathrm{P}$ at $5 \%$, respectively), considerably less phagocytic activity for zymosan became evident in cord leukocytes in lower serum concentrations (adult: $3.9 \pm 0.7$ and cord: $2.9 \pm 0.5$ at $2.5 \%$ ). Among cord serum specimens, there was noted no apparent correlation between opsonic activity and immunoglobulin or complement component levels. Higher values of IgA, IgM, C3 and Factor B in adult sera apparently contribute to a generally higher opsonic activity than that of cord sera.
\end{abstract}

\section{Speculation}

These results further substantiate the opinion that cord serum has less opsonic activity against certain test particles than adult serum and that cord leukocytes have lower oxidative metabolic responses than adult leukocytes as measured by oxygen consumption capacity. The importance of the choice of particles is stressed in interpreting the results, as opsonic requirements apparently differ from one particle to another. Although further studies are obviously necessary, the current method appears to be suitable for determining opsonic and phagocytic activities.

It is generally acknowledged that newborn infants are more susceptible to infections than adults and that this defect in the host defense mechanism is primarily due to a relative lack of humoral factors and to cellular functions as well $(2,3,4,8,9,10,12,15,17$, 22). Although there is fair agreement on the above notion, some inconsistencies have been noted in experimental results, which are probably due to the different designs and variable conditions in the performance of the experiments (11). The present investigation was undertaken to reevaluate the opsonic and phagocytic activities of cord serum and leukocytes, respectively, with assays based on the oxygen consumption capacity of leukocytes as well as on the opsonization time. The method used in this experiment turned out to be simple and reliable and appears to be applicable in the diagnosis of various opsonic and phagocytic disorders.

\section{MATERIALS AND METHODS}

After informed consent was obtained, cord blood specimens were obtained from 20 consecutive deliveries, which were at term and uncomplicated. The gestational age of the newborns ranged from 38-41 wk; 12 males and eight females. All were products of normal pregnancies and vaginal deliveries. Apgar scores were $\geq 9$ at 1 and $5 \mathrm{~min}$. Birth weights ranged from $2.6-4.3 \mathrm{~kg}$ with a mean of $3.2 \mathrm{~kg}$. The immediate neonatal period was uncomplicated. There was no clinical evidence of infectious disease during subsequent examinations in well-baby clinics. Cord serum and normal adult serum collected from 20 volunteers were stored separately in small aliquots at $-80^{\circ} \mathrm{C}$ until use. In some experiments, serum was pooled and stored similarly. Serum was diluted to specified final concentrations with HEPES buffer $(17 \mathrm{mM}$ N-hydroxyethylpiperazine- $\mathrm{N}^{\prime}$-ethanesulfonic acid, $\mathrm{pH} 7.4,120 \mathrm{mM} \mathrm{NaCl}, 5 \mathrm{mM}$ $\mathrm{KCl}, 1 \mathrm{mM} \mathrm{MgSO}_{4}, 1 \mathrm{mM} \mathrm{CaCl} 2$ and $5 \mathrm{mM}$ glucose). Heatinactivated serum was prepared by heating serum at $56^{\circ} \mathrm{C}$ for 30 min.

Separation of polymorphonuclear leukocytes (PMNL) from heparinized $(10 \mathrm{U} / \mathrm{ml})$ whole blood was performed following dextran sedimentation (3\% dextran, molecular weight 176,000 ), Ficoll-sodium metrizoate gradient and hypotonic lysis of residual erythrocytes. The interval between blood drawing and isolation of cells was kept as equal as possible for both cord and adult specimens. The purity of PMNL thus obtained was greater than 95\%. Their viability, estimated by trypan blue exclusion, was also greater than $95 \%$. They were used within $2 \mathrm{~h}$ after isolation, during which period no significant reduction of oxygen consumption capacity was noted. The blood type was matched between serum and PMNL, or type $O$ adult PMNL were used with cord serum and pooled type AB adult serum with cord PMNL.

Zymosan and three species of bacteria were used as particles to be opsonized. Zymosan A from $S$. cerevisiae (Sigma Chem. Co.) was washed and suspended in HEPES buffer and used at a concentration of $0.7 \mathrm{mg} / 10^{6}$ PMNL. Reference strains of Staphylococcus aureus 209P (S. aureus 209P), Escherichia coli NIHJ-JC2 (E. coli) and Streptococcus faecalis ( $S$. faecalis) were cultured in brain heart infusion broth for $18 \mathrm{~h}$ at $37^{\circ} \mathrm{C}$. Cultured organisms were washed three times in phosphate-buffered saline (PBS), pH 7.4 , and were suspended in PBS to give $5 \times 10^{9}$ bacteria $/ \mathrm{ml}$ using a spectrophotometric method. They were heat-killed and stored in aliquots at $-80^{\circ} \mathrm{C}$ until use. When bacteria were used as particles, the bacteria/PMNL ratio was 100:1 unless otherwise specified. Live bacteria were not routinely incorporated into the assay system because avid oxygen consumption by bacteria alone gave rise to a very high basal level, which made it more difficult 
to calculate subsequent smaller net increments in the presence of PMNL.

Oxygen consumption during phagocytosis was measured polarographically with a Clark type oxygen electrode (Yellow Springs Instrument Co.) as described by Nakamura et al. (13). The total reaction volume was $1.0 \mathrm{ml}$, which contained $2 \times 10^{6} \mathrm{PMNL}$ and the serum to be examined. Determination of opsonization time was also evaluated as proposed by Nakamura (14) and by Markert and Frei (7), although the latter authors attributed it to a delay of response, and was briefly summarized as follows. When unopsonized particles were added to PMNL suspended in test serum of different concentrations, the oxygen started to be consumed after a certain interval, which depended on the opsonin content. Opsonization time was defined as the interval between the addition of the particles and the point where two extrapolated lines intersect, one an extention of the resting phase and the other a linear portion of the phagocytizing phase. The amount of oxygen consumed was expressed as nmoles/min $/ 10^{6} \mathrm{PMNL}$. Following the determination of oxygen consumption, the reaction mixture was removed and washed three times with cold HEPES buffer at 250 $\times g$ for $5 \mathrm{~min}$. The cell pellet, suspended in $1.0 \%$ serum in HEPES buffer, was collected on a glass slide by Cytospin (ShannonElliott) and gram-stained for morphologic confirmation of the ingested particles.

Serum immunoglobulins and complement components were determined by single radial immunodiffusion methods.

The level of statistical significance was taken as $P<0.01$.

\section{RESULTS}

The opsonization time and oxygen consumption of the combination of adult PMNL and adult or cord serum with zymosan as phagocytizable particles are shown in Figure 1. The difference of opsonic activity was significant at a serum concentration of $10 \%$. At higher dilutions, the difference became more prominent for both opsonization time and oxygen consumption. Three of the 14 cord serum specimens could not be evaluated at $2.5 \%$ dilution because of the indefinitely prolonged opsonization time and virtually absent oxygen consumption and therefore were not included in this calculation. A significant inverse correlation between oxy-
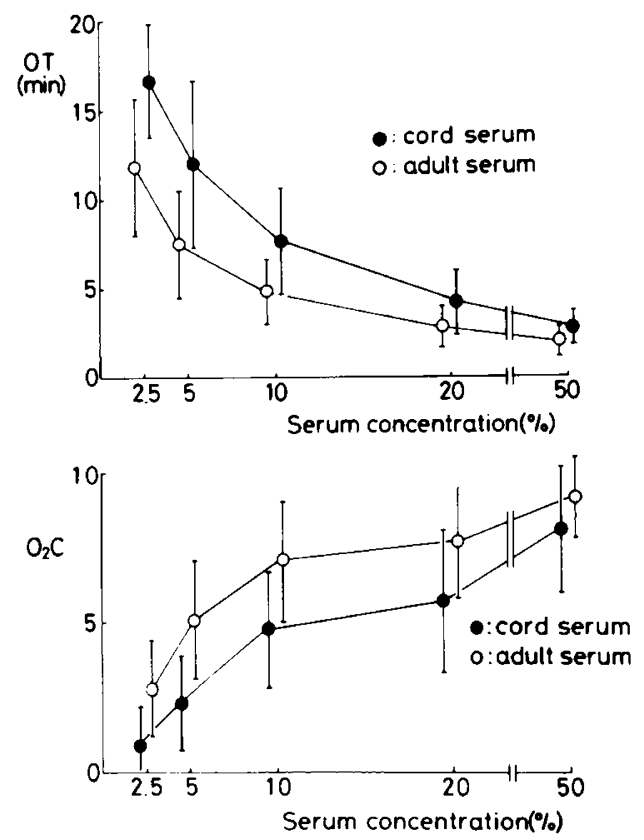

Fig. 1. Opsonization time (OT, min) and oxygen consumption $\left(\mathrm{O}_{2} \mathrm{C}\right.$, nmoles $\mathrm{O}_{2}$ consumed $/ \mathrm{min} / 10^{6} \mathrm{PMNL}$ ) of normal adult cells phagocytizing zymosans opsonized with various concentrations of adult serum $(n=20)$ or with cord serum $(n=14)$. Levels are expressed as mean \pm 1 S.D.

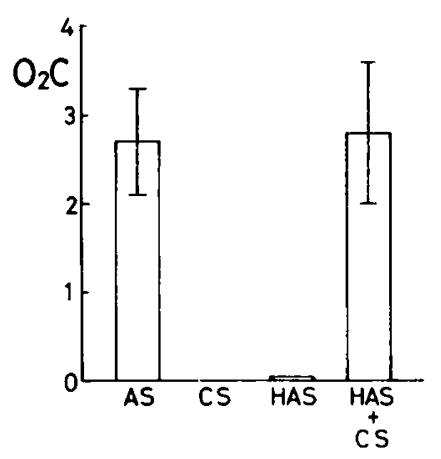

Fig. 2. Opsonic activity of adult (AS, $5 \%: n=10$ ), cord (CS, $5 \%: n=$ 5 ) and heated adult (HAS, 5\%: $n=10$ ) serum against killed $S$. faecalis as expressed by oxygen consumption $\left(\mathrm{O}_{2} \mathrm{C}\right)$ of adult PMNL.

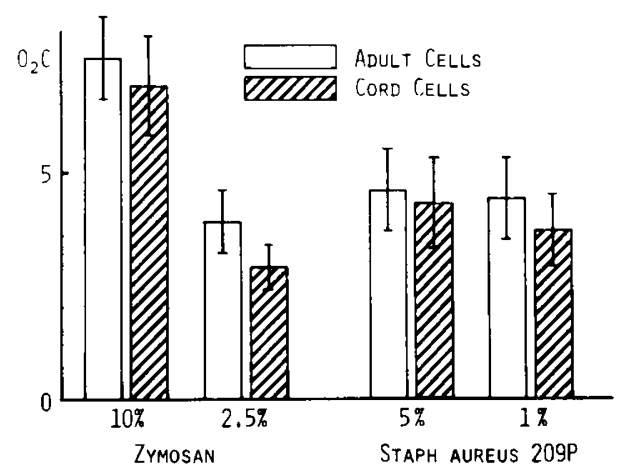

Fig. 3. Comparison of oxygen consumption $\left(\mathrm{O}_{2} \mathrm{C}\right)$ capacity of adult and cord PMNL with zymosan and killed $S$. aureus 209P as phagocytizable particles and with pooled fresh adult serum as opsonin.

gen consumption and opsonization time was found with either cord $(r=-0.97)$ or adult serum $(r=-0.98)$. In regard to cord serum, no correlation was found between opsonization time or oxygen consumption and IgG or any complement component level. Morphologic studies showed that zymosan particles opsonized with adult serum are ingested by PMNL, but those treated with cord serum failed to be engulfed. A reference $A B$ serum included in each determination gave almost consistent opsonization time and oxygen consumption by adult PMNL ( $\pm 5 \%$, respectively) for zymosan as well as for bacteria.

Ten adult and ten cord sera were compared for their opsonic activity against $S$. aureus $209 \mathrm{P}$ at $5 \%$ and $1 \%$ serum concentrations. Although there was an almost equal oxygen consumption at $5 \%$ (adult: $4.9 \pm 0.8$ and cord: $5.1 \pm 0.9$ ), a significant difference was noted with $1 \%$ serum (adult: $4.7 \pm 0.8$ and cord: $2.5 \pm 0.6$ ) Opsonization time, however, remained unchanged at these different dilutions and there was no significant difference between adult and cord serum. Adult PMNL were found to have ingested $S$. aureus 209P when opsonized with either adult or cord serum (5\%) after $15 \mathrm{~min}$ at $37^{\circ} \mathrm{C}$, but a precise quantification of ingested bacteria was not possible on the smears.

Cord serum was as effective as adult serum against $E$. coli as $10 \%$ and $5 \%$ serum concentrations: $1.5 \pm 0.6$ and $1.6 \pm 0.3$, respectively, at $10 \%$ and $1.0 \pm 0.5$ and $1.0 \pm 0.5$, respectively, at $5 \%$. Although oxygen consumption was still observed with further dilutions of both adult and cord serum, increasingly smaller amounts of consumed oxygen made it more difficult to quantify them accurately. Dilution of each serum equally resulted in some prolongation of the opsonization time, but not significantly from that at $10 \%$ serum concentration. Ingested $E$. coli could not be well visualized on slides because of their staining characteristics. Live bacteria were opsonized sufficiently with several specimens of cord serum.

In $5 \%$ adult serum $(n=10)$, oxygen consumption was $2.7 \pm 0.6$ 


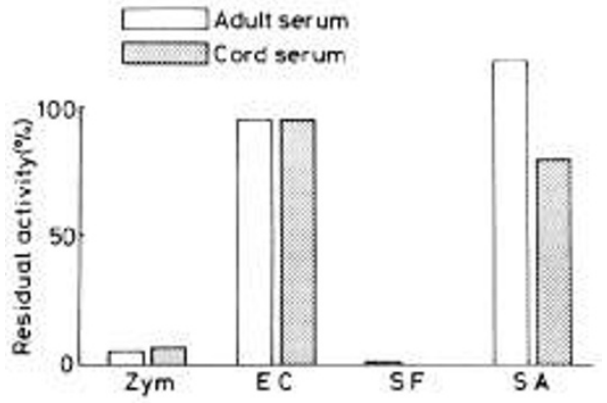

Fig. 4. Effect of heat inactivation $\left(56^{\circ} \mathrm{C}, 30 \mathrm{~min}\right)$ of pooled adult or cord serum on opsonic activity against zymosan (Zym), E. coli (EC), $S$. faecalis (SF) and $S$. aureus (SA). Each pre-heating activity was taken as $100 \%$.

and opsonization time $2 \mathrm{~min} 40 \mathrm{sec} \pm 30 \mathrm{sec}$ when adult PMNL ingested $S$. faecalis (Fig. 2). However, in cord serum no opsonic activity was seen at bacteria/PMNL ratios of $1: 1$ to $150: 1$ in $5 \%$ serum, or at higher serum concentrations $(10,20$ or $50 \%$ with a bacteria/PMNL ratio of 100:1). Cord serum added to adult serum failed to show any inhibitory activity. Lack of oxygen consumption was reflected in an almost complete absence of ingested bacteria in PMNL opsonized with cord serum compared with a cell ravenously phagocytizing bacteria treated with adult serum. Upon heating, adult serum lost its activity but still retained heat-stable opsonin, i.e., antibody. When heated pooled adult serum (antibody source) and fresh cord serum (complement source) were combined, resumption of normal activity was observed $(2.8 \pm 0.8$, Fig. 2$)$. Opsonization time, however, was 2 min longer than with adult serum; the reason for this remained unclear.

Adult and cord PMNL were compared for their capacity to consume oxygen when they ingested either zymosan or $S$. aureus 209P opsonized with pooled adult serum. Each particle was opsonized at two different concentrations, $10 \%$ and $2.5 \%$ for zymosan and $5 \%$ and $1 \%$ for S. aureus 209P. As shown in Figure 3, at higher serum concentrations, cord PMNL ingested both particles as well as did adult PMNL. At lower concentrations, however, oxygen consumption of cord PMNL was markedly reduced with zymosan, but the difference was not significant with $S$. aureus 209P.

Ten adult and ten cord sera were pooled separately, heatinactivated and assayed for their opsonic activity against the above four particles (Fig. 4). Both sera showed a similar tendency against three particles; marked reduction of activity against zymosan and $S$. faecalis (adult serum) and a minimal decrease against $E$. coli. However, an interesting difference was noted against $S$. aureus 209P; inactivation of pooled adult serum induced enhancement of oxygen consumption (118\%) while pooled cord serum lost $35 \%$ of its activity. When individual adult sera were heated, seven specimens showed an increase (range: 115-165\%) and three a decrease (range: 66-90\%) in comparison with their pre-heated activity. All cord sera showed decreased activity after heating.

Immunoglobulin and complement component values of cord sera $(n=12)$ were as follows (normal adult values in parentheses): $\mathrm{IgG}, 1159 \pm 217 \mathrm{mg} / \mathrm{dl}$ (mean \pm 1 S.D.) with a range of 939-1373 (800-1900); $\operatorname{IgA}$, all less than $20 \mathrm{mg} / \mathrm{dl}$ (80-380); IgM, all less than $15 \mathrm{mg} / \mathrm{dl}(50-300) ; \mathrm{C} 3,38.8 \pm 6.5 \mathrm{mg} / \mathrm{dl}$ with a range of $32.3-45.3$ (60-130); C4, $16.6 \pm 5.0 \mathrm{mg} / \mathrm{dl}$ with a range of 11.6-21.6 (20-40); $\mathrm{C} 5,72.7 \pm 16 \%$ with a range of $56.7-88.7 \%$ of the normal values; Factor B, $5.8 \pm 1.2 \mathrm{mg} / \mathrm{dl}$ with a range of 4.6-7.0 (10-20). Bilirubin concentration was less than $1.6 \mathrm{mg} / \mathrm{dl}$ in all sera.

\section{DISCUSSION}

Humoral and cellular factors related to phagocytosis in cord serum and in newborn infants have been the subject of numerous articles. The results accumulated so far have generally indicated that defective phagocytosis in the newborn is primarily due to a relative deficiency of opsonic activity and also to less effective cellular functions. However, there are some discrepancies in the conclusions, and as recently pointed out by Miller (11), they are probably due to differences in experimental designs, which include the assay system itself, the serum dilutions, the choice of particles, the cells used, etc. The present investigation confirmed and further extended the previous observations of the marginal opsonic deficiency of cord serum as well as the reduced, although slight, phagocytic capacity of cord polymorphonuclear leukocytes by determination of oxygen consumption of cells. Compared with the previously employed techniques, the current method appears to be objective and reproducible, and the amount of oxygen consumed tends to be more discriminative than the opsonization time. Throughout the course of this study, one of the major problems was the choice of particles, which has been found to play a decisive role in the interpretation of the results. Some discrepancies between the present and previous results are probably due to the different strains of the same species of bacteria, which makes the direct comparison of the results somewhat difficult.

Although most authors have recognized that $E$. coli is least likely to be opsonized with cord serum, one of the unexpected findings is that $E$. coli, both live and killed, was equally well opsonized by cord serum as thoroughly as by adult serum. This observation cannot be fully explained by the generally held concept that the major antibody against $E$. coli resides in the IgM fraction, which is mostly deficient in cord serum. The possibility that alterations of the membrane structures caused by heating might affect opsonization can be excluded by the fact that live bacteria were also well opsonized with cord serum. The analogy with staphylococcus (21) and its difference in opsonic requirements among strains may explain the present observations with this particular strain of $E$. coli.

All cord sera examined were totally lacking in opsonic activity against $S$. faecalis, which was also evident morphologically. With killed streptococcus, although not specified, Miyamoto (12) also showed a markedly lower phagocytic activity of leukocytes in newborn infants. However, normal activity was restored by the addition of heat-inactivated adult serum, which by itself is devoid of activity but retains antibody activity, to the cord serum, which preserves a sufficient amount of heat-labile opsonin, i.e., complement, as evidenced by opsonization of zymosan. This finding suggests that both complement and antibody are needed to participate synergistically in the optimal opsonization of $S$. faecalis. Such a complete absence of antibody for this organism may be due to a lack of transplacental transfer of maternal antibody, an opposite situation to that of group B streptococcus for the antibody level of which has been demonstrated to be the same in cord serum as in adult serum (5).

A marked reduction of activity of both cord and adult heated serum against zymosan and $S$. faecalis in adult serum indicates that heat-labile opsonins are indispensable factors against these particles, and the relative persistence of opsonic activity against $E$. coli suggests that heat-stable opsonins, antibodies, play a major role in opsonization. However, heat treatment of adult serum increased the opsonic activity of adult serum against $S$. aureus 209P. In higher concentrations, heated adult serum caused greater oxygen consumption than corresponding concentration of fresh serum. The presence of some inhibitory factor(s) in fresh serum, which can be eliminated by heating, is postulated and under study.

A low complement level by itself is not necessarily reflected in a low opsonic activity. This situation is exemplified in another series of experiments by the hypocomplementemic serum of a patient with acute glomerulonephritis, which contained $16 \mathrm{mg} / \mathrm{dl}$ of $\mathrm{C} 3$ but $19 \mathrm{mg} / \mathrm{dl}$ of Factor B. The observation that this serum showed normal activity against zymosan but also against other particles raises the possibility that the normal level of Factor B may support an effective opsonization of zymosan, even if the $\mathrm{C} 3$ level is far below that of cord serum. This also seems to be compatible with the findings of Stossel et al. (17) that defective opsonic activity for paraffin oil particles is associated with a subnormal level of Factor B and is not correlated with $C 3$ concentration, although our results indicate that the opsonic activity of 
cord serum of healthy newborns is not correlated at all with the corresponding C3 or Factor B levels.

The oxidative metabolism of cord polymorphonuclear leukocytes has been investigated in various ways, some of which are not yet conclusive, as in the case of chemiluminescence $(1,16,18$, $20)$ or glucose consumption $(6,16)$. Park et al. (15) demonstrated that leukocytes of newborn infants showed normal increments not only of oxygen consumption but also of hexose monophosphate shunt activity and NBT reduction, and concluded that newborn phagocytes are functionally mature cells. The results reported here also showed a normal capacity of oxygen consumption, unless cord cells are obliged to ingest particles opsonized with highly diluted serum. The reduction of oxygen consumption during stress suggests that cord leukocytes are still marginally deficient in metabolic reserve capacity. Although bilirubin has been reported to inhibit phagocytosis and bactericidal capacity (19), in low concentrations, as seen in the current specimens, it had no untoward effect on oxygen consumption.

\section{REFERENCES AND NOTES}

1. Anderson, D., and Huntsberger, E. M.: Luminol enhanced chemiluminescence of neonatal granulocytes and monocytes. Pediatr. Res., 12: 476 (1978).

2. Dossett, J. H., Williams, R. C., Jr., and Quie, P. G.: Studies on interaction of bacteria, serum factors and polymorphonuclear leukocytes in mothers and newborns. Pediatrics, 44: 49 (1969).

3. Forman, M. L., and Stiehm, E. R.: Impaired opsonic activity but normal phagocytosis in low-birth-weight infants. New Engl. J. Med., 281: 926 (1969).

4. Gluck, L., and Silverman. W. A.: Phagocytosis in premature infants. Pediatrics, 20: 951 (1957).

5. Hemming, V. G., Hall, R. T., Rhodes, P. G., Shigeoka, A. O., and Hill, H. R.: Assessment of group B streptococcal opsonins in human and rabbit serum. $\mathbf{J}$. Clin. Invest., $58: 1379$ (1976).

6. Jemelin, M., Fornerod, M., Frei, J., and Prod'hom, L. S.: Impaired phagocytosis in leukocytes from newborn infants. A study of glycolysis and activities of phosphoglycerate kinase and pyruvate kinase. Enzyme, 12: 642 (1971).

7. Markert, M., and Frei, J.: The energy metabolism of the leucocyte. X. Kinetics of oxygen consumption during phagocytosis by polymorphonuclear leucocytes. A photometric method. Enzyme, 24: 327 (1979).

8. Matoth, Y.: Phagocytic and ameboid activities of the leukocytes in the newborn infant. Pediatrics, 9: 748 (1952)

9. McCracken, G. H., Jr., and Eichenwald, H. F.: Leukocyte function and the development of opsonic and complement activity in the neonate. Amer. J. Dis. Child., 121: 120 (1971).

10. Miller, M. E.: Phagocytosis in the newborn infant: humoral and cellular factors. J. Pediatr., 74: 255 (1969).

11. Miller, M. E.: Phagocyte function in the neonate: selected aspects. Pediatrics 64(Part 2): 709 (1979).

12. Miyamoto, K.: Phagocytic activity of leucocytes in premature infants. Part I Comparison of the phagocytic activity of leucocytes between premature infants and full-term infants. Hiroshima J. Med. Sci., 14: 9 (I965).

13. Nakamura, M., Nakamura, M., Okamura, J., and Kobayashi, Y.: A rapid and quantitative assay of phagocytosis-connected oxygen consumption by leukocytes in whole blood. J. Lab. Clin. Med., 91: 568 (1978).

14. Nakamura, M.: In: Leukocyte and Phagocytosis.' Eds. Minakami, S. and Kakinuma, K., p. 213, (Kodansha Scientific Co. 1979) (In Japanese).

15. Park, B. H., Holmes, B., and Good, R. A.: Metabolic activities in leukocytes of newborn infants. J. Pediatr., $76: 237$ (1970).

16. Shigeoka, A. O., Allred, C. D., and Hill, A. R.: Chemiluminescence response of neonatal leukocytes. Pediatr. Res., 12: 486 (1978).

17. Stossel, T. P., Alper, C. A., and Rosen, F. S.: Opsonic activity in the newborn: role of properdin. Pediatrics, 52: 134 (1973).

18. Strauss, R. G., and Seifert. M. J.: Oxidative metabolism in cord-blood polymorphonuclear leucocyte. Arch. Dis. Child., 53: 476 (1978).

19. Thong, Y. H., Ferrante, A., and Ness, D.: Neutrophil phagocytic and bactericidal dysfunction induced by bilirubin. Aust. Paediatr. J., I3: 287 (1977).

20. Van Epps, D. E., Goodwin, J. S., and Murphy, S.: Age-dependent variations in polymorphonuclear leukocyte chemiluminescence. Infect. Immun., 22: 57 (1978).

21. Verhoef, J., Peterson, P. K., Kim, Y., Sabath, L. D., and Quie, P. G.: Opsonic requirements for staphylococcal phagocytosis. Heterogeneity among strains. Immunology, 33: 191 (1977).

22. Xanthou, M., Valassi-Adam, E., Kintzonidou, E., and Matsaniotis, N.: Phagocytosis and killing ability by leucocytes of healthy term and preterm babies. Arch. Dis. Child., 50: 72 (1975).

23. The authors express their sincere gratitude to Dr. Akira Yorishima for his efforts in procuring cord blood specimens. This work was supported in part by a Grant-in-Aid from the Japan Medical Research Foundation and Grants-inAid (Project No. 157253 and 544050) from the Ministry of Education, Science and Culture of Japan.

24. Requests for reprints should be addressed to: Dr. Yohnosuke Kobayashi, Department of Pediatrics, Hiroshima University School of Medicine, Kasumi 12-3, Minami-ku, Hiroshima 734, Japan.

25. Received for publication February 13, 1981

26. Accepted for publication July 8,1981 . 